\title{
Systematic Literature Review of Agile Scalability for Large Scale Projects Agile Scalability and Adoptability
}

\author{
Hina saeeda \\ Department of Computer Software Engineering \\ MCS, National University of Sciences and Technology, \\ Rawalpindi, Pakistan \\ Hannan Khalid \\ Department of Computer Sciences \\ COMSATS Institute of Information Technology \\ Islamabad, Pakistan
}

\author{
Mukhtar Ahmed \\ Department of Computer Sciences \\ COMSATS Institute of Information Technology \\ Islamabad, Pakistan \\ Abu Sameer \\ Department of Computer Sciences \\ COMSATS Institute of Information Technology \\ Islamabad, Pakistan
}

\author{
Fahim Arif \\ Department of Computer Software Engineering \\ MCS, National University of Sciences and Technology, \\ Rawalpindi, Pakistan
}

\begin{abstract}
In new methods, "agile" has come out as the top approach in software industry for the development of the soft wares. With different shapes agile is applied for handling the issues such as low cost, tight time to market schedule continuously changing requirements, Communication \& Coordination, team size and distributed environment. Agile has proved to be successful in the small and medium size project, however, it have several limitations when applied on large size projects. The purpose of this study is to know agile techniques in detail, finding and highlighting its restrictions for large size projects with the help of systematic literature review. The systematic literature review is going to find answers for the Research questions: 1) How to make agile approaches scalable and adoptable for large projects?2) What are the existing methods, approaches, frameworks and practices support agile process in large scale projects? 3) What are limitations of existing agile approaches, methods, frameworks and practices with reference to large scale projects? This study will identify the current research problems of the agile scalability for large size projects by giving a detail literature review of the identified problems, existed work for providing solution to these problems and will find out limitations of the existing work for covering the identified problems in the agile scalability. All the results gathered will be summarized statistically based on these findings. Remedial work will be planned in future for handling the identified limitations of agile approaches for large scale projects.
\end{abstract}

Keywords-Agility; large scale projects; agile scalability; SCRUM; XP; DSDM; Crystal; SLR; Statistical Analysis

\section{INTRODUCTION}

In market, different types of agile techniques such as SCRUM, DSDM, CRYSTAL, XP, XP2 are there each type of agile is having some different type of and specific property in it .While we talk about agile methods it is very good in the small and medium size project [1]. Agile are a combination of the characteristics that make the project successful these qualities make the project to have good properties according to the market [2]. The agile benefits such as minimum documentation, pair programming, and high teamwork produce good results for the small and medium level projects large size projects are also using the approaches but with certain limitations [3]. On the other hand, when we apply the agile approaches to large size projects it does not provide the same results.

When talking About scalability of agile two terminologies are in use "Scaling out" and "scaling up" Scaling up' is dealing with using agile methods for developing large software systems that cannot be developed by a small team. Scaling out' is concerned with how agile methods can be used in large size projects [4].

It is not the true that 100 percent its application is going to fail but like the small level and medium level projects results, it does not show the same for large size projects. The agile approaches such as crystal - blue are in use for large size projects but show less agile properties. [5]. Techniques of agility like SCRUM are applied for the large size project but it has also some restrictions [6].

The current research is about scaling of agile techniques for large size projects [7]. The discussion on ability of agile practices to scale to "large" software development efforts has been widely discussed [8][64]. Here the purpose of the research is to conduct detailed literature review on the agile scalability, identifying current work done for agile scalability and limitations faced by agility in large size projects. In a systematic way, In study proper research questions are built according to the PICOC structure against each question 
research strings are built for different search strings including, IEEE, ACM, GOOGLE SCHOLAR and SCIENCE DIRECT .

Data bases are created against each search strings and search protocol is applied on the data bases for final selection of papers, with help of data extraction forms data from each selected paper is extracted and reviewed statistically. Research Questions for Study

Research Question 1: How to make agile approaches scalable and adoptable for large projects?

Research Question 2: What are the existing methods, approaches, frameworks and practices support agile process in large scale projects?

Research Question 3: What are limitations of existing agile approaches, methods, frameworks and practices with reference to large scale projects?

\section{PROTOCOL FOR SEARCH PROCESS}

After specifying research questions a review protocol is developed, this includes the definition of the following:

- The Search Process

- Inclusion And Exclusion Criteria

- The Selection Process

- The Data Extraction Process

- Data Synthesis

\section{SOURCES (DIGITAL LIBRARIES) FOR LITERATURE SEARCH}

The following databases are search out for primary studies Google Scholar, IEEE, Science Direct and ACM

\section{RESEARCH QUESTIONS IN PICOC STRUCTURE}

A. RQ1: How to make agile approaches scalable and adoptable for large scale projects?

- Population: Agile Approaches

- Intervention: Large scale projects

- Outcome: Parameters for scalability and adoptability

1) Search strings/Second Step: Synonyms

a) Population

"Agile Approaches "; "Agile software development approaches "; "Agile software development techniques "; "Agile software engineering"; "Agile software methodologies "; "Agile software engineering methodologies "; "Agile software development approaches "; "Agile software engineering methods "; "Agile software engineering methodologies "; "Agile software development processes "; "Agile software engineering practices".

\section{b) Intervention}

"Large scale Projects"; "Big scale Projects"; "Vast scale Projects"; "Large size Projects"; Big size Projects"; vast size Projects". c) Outcome

"Parameters for scalability and adoptability"; "methods for scalability and adoptability"; ways for scalability and adoptability "; strategies for scalability and adoptability"

\section{2) Search Strings Used for Primary Studies of Research} question one

Database Search String

((“““'Agile Approaches ”OR "Agile software development approaches "OR "Agile software development techniques "OR "Agile software engineering "OR "Agile software methodologies "OR "Agile software engineering methodologies "OR "Agile software development approaches "OR "Agile software engineering methods "OR "Agile software engineering methodologies "OR "Agile software development processes OR "Agile software engineering practices" AND("Large scale Projects" OR "Big scale Projects " OR "Vast scale Projects" OR "Large size Projects" OR Big size Projects" OR vast size Projects") AND ("parameters for scalability and adoptability "OR "methods for scalability and adoptability "OR ways for scalability and adoptability "OR strategies for scalability and adoptability"'))

((““”Agile Approaches ”OR “Agile software development approaches "OR "Agile software development techniques "OR "Agile software engineering "OR "Agile software methodologies "OR "Agile software engineering methodologies "OR "Agile software development approaches "OR "Agile software engineering methods "OR "Agile software engineering methodologies "OR "Agile software development processes OR "Agile software engineering practices" AND ("Large scale Projects" OR "Big scale Projects " OR "Vast scale Projects" OR "Large size Projects" OR Big size Projects" OR vast size Projects") AND ("parameters for scalability and adoptability "OR "methods for scalability and adoptability "OR ways for scalability and adoptability "OR strategies for scalability and adoptability"'))

((““'Agile Approaches ”OR “Agile software development approaches "OR "Agile software development techniques "OR "Agile software engineering "OR "Agile software methodologies "OR "Agile software engineering methodologies "OR "Agile software development approaches "OR "Agile

Science software engineering methods "OR "Agile software engineering Direct "Agile software engineering practices" AND ("Large scale Projects" OR "Big scale Projects " OR "Vast scale Projects" OR "Large size Projects" OR Big size Projects" OR vast size Projects") AND ("parameters for scalability and adoptability "OR "methods for scalability and adoptability "OR ways for scalability and adoptability "OR strategies for scalability and adoptability"'))

((““”Agile Approaches ”OR “Agile software development approaches "OR "Agile software development techniques "OR "Agile software engineering "OR "Agile software methodologies "OR "Agile software engineering methodologies "OR "Agile software development approaches "OR "Agile software engineering methods "OR "Agile software engineering methodologies "OR "Agile software development processes OR "Agile software engineering practices" AND ("Large scale Projects" OR "Big scale Projects" OR "Vast scale Projects" OR "Large size Projects" OR Big size Projects" OR vast size Projects") AND ("parameters for scalability and adoptability "OR "methods for scalability and adoptability "OR ways for scalability and adoptability "OR strategies for scalability and adoptability"')) 
B. RQ2: What are the existing methods, approaches, frameworks and practices support agile process in large scale projects?

\section{1) Search strings/Second Step: Synonyms}

a) Population

"Agile Approaches "; "Agile software development approaches "; "Agile software development techniques "; "Agile software engineering"; "Agile software methodologies "; "Agile software engineering methodologies "; "Agile software development approaches "; "Agile software engineering methods "; "Agile software engineering methodologies "; "Agile software development processes "; "Agile software engineering practices".

\section{b) Intervention}

"Large scale Projects"; "Big scale Projects"; "Vast scale Projects"; "Large size Projects"; Big size Projects"; vast size Projects".

\section{c) Outcome}

"methods"; "approaches"; frameworks "; practices".

2) Search Strings Used for Primary Studies of Research question Two Search String

((““'Agile Approaches ”OR “Agile software development approaches "OR "Agile software development techniques "OR "Agile software engineering "OR "Agile software methodologies "OR "Agile software engineering methodologies "OR "Agile software development approaches

IEEE "OR "Agile software engineering methods "OR "Agile software engineering methodologies "OR "Agile software development processes OR "Agile software engineering practices" AND ("Large scale Projects" OR "Big scale Projects " OR "Vast scale Projects" OR "Large size Projects" OR Big size Projects" OR vast size Projects") AND ("methods "OR "approaches "OR frameworks "OR practices"”))

((““"Agile Approaches ”OR “Agile software development approaches "OR "Agile software development techniques "OR "Agile software engineering "OR "Agile software methodologies "OR "Agile software engineering methodologies "OR "Agile software development approaches "OR "Agile software engineering methods "OR "Agile software engineering methodologies "OR "Agile software development processes OR "Agile software engineering practices" AND ("Large scale Projects" OR "Big scale Projects " OR "Vast scale Projects" OR "Large size Projects" OR Big size Projects" OR vast size Projects") AND ("methods "OR "approaches "OR frameworks "OR practices"”))

((““'Agile Approaches ”OR "Agile software development approaches "OR "Agile software development techniques "OR "Agile software engineering "OR "Agile software methodologies "OR "Agile software engineering

Science methodologies "OR "Agile software development approaches

Science "OR "Agile software engineering methods "OR "Agile software Direct engineering methodologies "OR "Agile software development processes OR "Agile software engineering practices" AND ("Large scale Projects" OR "Big scale Projects " OR "Vast scale Projects" OR "Large size Projects" OR Big size Projects" OR vast size Projects") AND ("methods "OR "approaches "OR frameworks "OR practices"”))

((““"Agile Approaches ”OR “Agile software development approaches "OR "Agile software development techniques "OR "Agile software engineering "OR "Agile software methodologies"OR "Agile software engineering methodologies "OR "Agile software development approaches

Google

Scholar "OR "Agile software engineering methods "OR "Agile software engineering methodologies "OR "Agile software development processes OR "Agile software engineering practices" AND ("Large scale Projects" OR "Big scale Projects " OR "Vast scale Projects" OR "Large size Projects" OR Big size Projects" OR vast size Projects") AND ("methods "OR “approaches "OR frameworks "OR practices "'))

C. RQ3: what are limitations of existing agile approaches, methods, frameworks and Practices with reference respect to large scale projects?

\section{1) Search strings/Second Step: Synonyms}

\section{a) Population}

"Agile Approaches "; "Agile software development approaches "; "Agile software development techniques "; "Agile software engineering"; "Agile software methodologies "; "Agile software engineering methodologies "; "Agile software development approaches "; "Agile software engineering methods "; "Agile software engineering methodologies "; "Agile software development processes "; "Agile software engineering practices".

\section{b) Intervention}

"Large scale Projects"; "Big scale Projects"; "Vast scale Projects"; "Large size Projects"; Big size Projects"; vast size Projects".

\section{c) Outcome}

"Limitations of methods"; "limitations of approaches";" limitations of frameworks ";" limitations of practices".

2) Search Strings Used for Primary Studies Search Strings Used for Primary Studies of Research question Three

Database Search String

((““”Agile Approaches ”OR "Agile software development approaches "OR "Agile software development techniques "OR "Agile software engineering "OR "Agile software methodologies "OR "Agile software engineering methodologies "OR "Agile software development approaches "OR "Agile software engineering methods "OR "Agile software engineering methodologies "OR "Agile software development processes OR "Agile software engineering practices" AND ("Large scale Projects" OR "Big scale Projects " OR "Vast scale Projects" OR "Large size Projects" OR Big size Projects" OR vast size Projects") AND ("limitations of methods "OR " limitations of approaches "OR limitations of frameworks "OR limitations of practices ")))

((““"Agile Approaches "OR "Agile software development approaches "OR "Agile software development techniques "OR "Agile software engineering "OR "Agile software methodologies "OR "Agile software engineering methodologies "OR "Agile software development approaches "OR "Agile software engineering methods "OR "Agile software engineering methodologies "OR "Agile software development processes OR "Agile software engineering practices" AND ("Large scale Projects" OR "Big scale Projects " OR "Vast scale Projects" OR "Large size Projects" OR Big size Projects" OR vast size Projects") AND ("limitations of 
methods "OR " limitations of approaches "OR limitations of frameworks "OR limitations of practices"”))

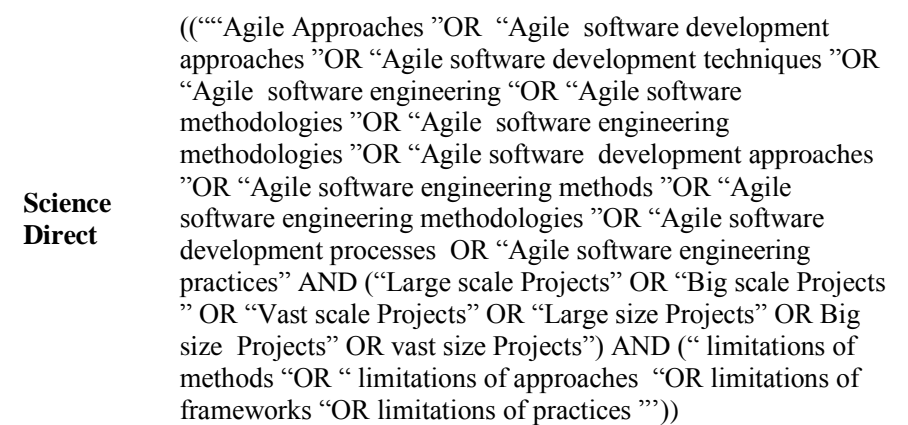

((““'Agile Approaches ”OR “Agile software development approaches "OR "Agile software development techniques "OR "Agile software engineering "OR "Agile software methodologies "OR "Agile software engineering methodologies "OR "Agile software development approaches

Google Scholar "OR "Agile software engineering methods "OR "Agile software engineering methodologies "OR "Agile software development processes OR "Agile software engineering practices" AND ("Large scale Projects" OR "Big scale Projects " OR "Vast scale Projects" OR "Large size Projects" OR Big size Projects" OR vast size Projects") AND (" limitations of methods "OR " limitations of approaches "OR limitations of frameworks "OR limitations of practices "'))

\section{Publication QuAlity Assessment}

The data extraction form is designed as it will extract the data form finally selected papers assessing their quality and searching answers for research questions.

\section{Detail of quality assessment 1-5:}

Study provides detailed description of agile scalability? The possible answers to this question are: "Yes $(+1)$ "' if the paper provides detail description of agile scalability; " partially $(0)$ " if the paper provides partial or not detail information about agile scalability; and "No ( 1 )", if the paper does not provide any information about agile scalability.

The study provides the guideline as how the agile techniques are used in large size projects? The possible answers to this question are: "Yes $(+1)$ "' if the paper provides information as how the agile techniques are used in large size projects; "partially (0)" if the paper provides partial or not detail information as how the agile techniques are used in large size projects; and "No ( 1$)$ " if the paper does not provide any information as how the agile techniques are used in large size projects.

The study provides clear results after application of agile techniques in large size projects?

The possible answers to this question are: "Yes $(+1)$ "' if the paper provides clear results; "partially (0)" if the paper provides partial or not detail results; and "No ( 1$)$ ", if the paper does not provide any results.

The study has been published in a relevant journal or conference proceedings. The possible answers to this question are: "Very relevant", (+1), "Relevant (0)", and "Not so relevant (1)'”.

This question will be rated by considering the order of relevance provided by the digital library, the CORE conference ranking (A, B and $\mathrm{C}$ conferences), and the Journal Citation Reports (JCR) lists.

The study has been cited by other authors. The possible answers to this question are: "Yes $(+1)$ "' if the paper has been cited by more than five authors; " $p$ artially $(0)$ ", if the paper has been cited by 1-5 authors; and "No ( 1$)$ " if the paper has not been cited. This question was rated by considering the Google scholar citations count.

TABLE I. DATA EXTRACTION FORM

\begin{tabular}{|l|l|}
\hline Paper Title: & Year of Publication: \\
\hline Authors: & $\begin{array}{l}\text { Publisher: } \\
\text { IEEE/ACM/Google Scholar/Science Direct }\end{array}$ \\
\hline Reference Type: Journal/Conference/Thesis/Unpublished & $(\mathbf{1})$ \\
\hline \multicolumn{2}{|l|}{$(\mathbf{0})$} \\
\hline Quality Assessment & \\
\hline Study provides detailed description of agile scalability? & \\
\hline $\begin{array}{l}\text { The study provides the guideline as how the agile techniques are used } \\
\text { in large size projects? }\end{array}$ & \\
\hline $\begin{array}{l}\text { The study provides clear results after application of agile techniques in } \\
\text { large size projects? }\end{array}$ & \\
\hline The study has been published in a relevant journal or conference? & \\
\hline The study has been cited by other authors? & \\
\hline \multicolumn{2}{|l|}{} \\
\hline Data extraction for Questions & Answers \\
\hline What methods have been employed by researchers to make Agile scalable for large size projects? \\
\hline $\begin{array}{l}\text { 1.1. Phase(s) of software process in which the Agile techniques are } \\
\text { applied for scalability? }\end{array}$ & $\begin{array}{l}\text { Requirement } \\
\text { Design } \\
\text { Implementation } \\
\text { Testing } \\
\text { Maintenance }\end{array}$ \\
\hline 1.2. Which Agile technique has been reported in this study? & Technique Name \\
\hline 1.3. Data characteristics & $\begin{array}{l}\text { Academia } \\
\text { mixed } \\
\text { Industrial }\end{array}$ \\
\hline
\end{tabular}




\begin{tabular}{|c|c|}
\hline & Government \\
\hline Research detects agile limitations for large size project? & $\begin{array}{l}\text { Documentation } \\
\text { Time period } \\
\text { Budget } \\
\text { Human resources } \\
\text { Coordination } \\
\text { Distributed environment } \\
\text { others }\end{array}$ \\
\hline $\begin{array}{l}\text { Empirical Validation of the agile techniques applied in large size } \\
\text { projects. }\end{array}$ & $\begin{array}{l}\text { Case Study } \\
\text { Experiment } \\
\text { Survey } \\
\text { experience reports } \\
\text { observational study, survey } \\
\text { action research } \\
\text { No }\end{array}$ \\
\hline
\end{tabular}

VI. GENERAL INFORMATION REGARDING RESEARCH PAPER

The below table represent the general information of papers studied in the SLR process all these papers were finalized for study process, so that the specific information from theses papers can be gathered according to the research questions designed.

TABLE II. GENERAL INFORMATION REGARDING RESEARCH PAPER

\begin{tabular}{|c|c|c|c|c|c|}
\hline \multirow[t]{2}{*}{ Sr. No } & \multicolumn{5}{|c|}{ General information regarding research papers } \\
\hline & Title & Author(s) & Database & $\begin{array}{l}\text { Journal ./Conf./ } \\
\text { Work. }\end{array}$ & Year \\
\hline 1 & $\begin{array}{l}\text { Identifying some important success } \\
\text { factors in adopting agile software } \\
\text { development practices }\end{array}$ & $\begin{array}{l}\text { Subhas Chandra Misra a, } \\
\text { Vinod Kumar b, } \\
\text { Uma Kumar b }\end{array}$ & $\mathrm{ACM}$ & Journal & 2009 \\
\hline 2 & $\begin{array}{l}\text { Strengths and barriers behind the } \\
\text { successful agile deployment-insights } \\
\text { from the three software intensive } \\
\text { companies in Finland }\end{array}$ & $\begin{array}{l}\text { Minna Pikkarainen \& Outi } \\
\text { Salo \& Raija Kuusela \& Pekka } \\
\text { Abrahamsson }\end{array}$ & $\mathrm{ACM}$ & Journal & 2011 \\
\hline 3 & $\begin{array}{l}\text { Acceptance of agile methodologies: A } \\
\text { critical review and conceptual } \\
\text { framework }\end{array}$ & $\begin{array}{l}\text { Frank K.Y. Chan, } \\
\text { James Y.L. Thong }\end{array}$ & Google Scholar & Journal & 2008 \\
\hline 4 & $\begin{array}{l}\text { A Study of the Agile Software } \\
\text { Development Methods, Applicability } \\
\text { and Implications in Industry }\end{array}$ & $\begin{array}{l}\text { Kuda Nageswara Rao, } \\
\text { G. Kavita Naidu, } \\
\text { Praneeth Chakka }\end{array}$ & Google Scholar & Conference & 2011 \\
\hline 5 & $\begin{array}{l}\text { 'State of the Art' in Using Agile } \\
\text { Methods for Embedded Systems } \\
\text { Development }\end{array}$ & $\begin{array}{l}\text { Jayakanth Srinivasan, } \\
\text { Radu Dobrin, Kristina } \\
\text { Lundqvist }\end{array}$ & Google Scholar & Journal & 2009 \\
\hline 6 & $\begin{array}{l}\text { An Empirical Study: Understanding } \\
\text { Factors and Barriers for Implementing } \\
\text { Agile Methods in Malaysia }\end{array}$ & $\begin{array}{l}\text { Ani Liza Asnawi, } \\
\text { Andrew M Gravell, } \\
\text { Gary B Wills }\end{array}$ & Google Scholar & Conference & 2010 \\
\hline 7 & $\begin{array}{l}\text { Distributed Scrum: Agile Project } \\
\text { Management with Outsourced } \\
\text { Development Teams }\end{array}$ & $\begin{array}{l}\text { Jeff Sutherland, } \\
\text { Anton Viktorov, } \\
\text { Jack Blount,Nikolai } \\
\text { Puntikov }\end{array}$ & Google Scholar & Conference & 2007 \\
\hline 8 & $\begin{array}{l}\text { Agile methods in European embedded } \\
\text { software development organizations: a } \\
\text { survey on the actual use and } \\
\text { usefulness of Extreme Programming } \\
\text { and Scrum }\end{array}$ & $\begin{array}{l}\text { O. Salo and P. } \\
\text { Abrahamsson }\end{array}$ & Google Scholar & Conference & 2007 \\
\hline 9 & $\begin{array}{l}\text { The Impact of Scaling on Planning } \\
\text { Activities in an Agile Software } \\
\text { Development Context }\end{array}$ & Hubert Smits & Google Scholar & Conference & 2007 \\
\hline 10 & $\begin{array}{l}\text { Rolling out Agile in a Large } \\
\text { Enterprise }\end{array}$ & Gabrielle Benefield & Google Scholar & Conference & 2008 \\
\hline 11 & $\begin{array}{l}\text { An Appraisal of Existing Evaluation } \\
\text { Frameworks for Agile Methodologies }\end{array}$ & $\begin{array}{l}\text { Masoumeh Taromirad, } \\
\text { Raman Ramsin }\end{array}$ & Google Scholar & Conference & 2008 \\
\hline 12 & $\begin{array}{l}\text { Implementing Program Model with } \\
\text { Agile Principles in a Large Software } \\
\text { Development Organization }\end{array}$ & Maarit Laanti & Google Scholar & Conference & 2008 \\
\hline 13 & $\begin{array}{l}\text { A Soft-Structured Agile Framework } \\
\text { for Larger Scale Systems } \\
\text { Development }\end{array}$ & $\begin{array}{l}\text { Shvetha } \\
\text { Soundararajan and } \\
\text { James D. Arthur }\end{array}$ & Google Scholar & Conference & 2009 \\
\hline 14 & $\begin{array}{l}\text { FORMAL VERSUS AGILE: } \\
\text { SURVIVAL OF THE FITTEST? }\end{array}$ & $\begin{array}{l}\text { Sue Black, Paul P. Boca, Jonathan P. } \\
\text { Bowen, Jason Gorman, } \\
\text { Mike Hinchey, }\end{array}$ & Google Scholar & Conference & 2009 \\
\hline 15 & Agile Adoption Experience : A Case & Hassan Hajjdiab and & Google Scholar & Thesis & 2011 \\
\hline
\end{tabular}


Study in the U.A.E

Agile Method to Improve Delivery of

IBM agility@scale ${ }^{\mathrm{TM}}$ : Become as Agile as You Can Be

Agile Framework for Globally Distributed Development Environment (The DAD Model)

19 Complex software project development: agile methods adoption

Designing an Information Systems

Development Course to Incorporate Agility, Flexibility, and Adaptability

Innovation and Scaling up Agile

21 Software Engineering Projects

Agile Software Development in the Large

Agile Framework for Globally

23 Distributed Development Environment (The DAD Model)

Scrum Practices in Global Software Development: A Research Framework

Usage and Perceptions of Agile Software Development in an Industrial Context: An Exploratory Study Agile methods for cloud computing

Agile Software Product Lines - A Working Session Designing an information systems development course to incorporate agility, flexibility, and adaptability

Using XP in Telecommunication

Software Development

Experiences Applying Agile Practices

to Large Systems

A Heavy Weight IT Project

29 Management Framework based on Agile Theory

ESCAPE THE WATERFALL: AGILE FOR AEROSPACE

Enterprise Scrum: Scaling Scrum to

the Executive Level

Agility in a Large-Scale System

Engineering Project: A Case-Study of an Advanced Communication System Project

33 Software Development as a Service: Agile Experiences

Agile Way of BI Implementation
Al Shaima Taleb

Mary Wu

Google Scholar

Journal

2011

By Scott W. Ambler Chief

Methodologist for Agile and Lean,

IBM Rational

2010

Rehan Akbar

Muhammad

Haris , Majid Naem

Google Scholar Journal

2008

Deepti Mishra?,†

and

Alok Mishra-fan Dai and

Google Scholar

Journal

Ming-li Wang

Chuan-Hoo Tan

Wee-Kek Tan Hock-Hai Teo

Google Scholar Journal

2009

Sita Ramakrishnan

Google Scholar

Thesis

2009

Jutta Eckstein

Reahan Akbar,

Muhammad Haris

and MajidNaeem

Mohammed

Abdullah Alnuem,

Arshad Ahmad and

Hashim Khan

Google Scholar

Conference

2008

Google Scholar

Conference

Emam Hossain,

Paul L. Bannerman, and

D. Ross Jeffery

IEEE

Conference

Andrew Begel,

Nachiappan Nagappan

IEEE

Conference

2009

John D. McGregor

Ensar Gul Multitek Arge Istanbul,Turkey

IEEE

Conference

2009

IEEE

Conference

2009

Harry Koehnemann,

Chen jianbin Business

Steven H. VanderLeest,

IEEE

Conference

2010

IEEE

Conference

2010

IEEE

Conference

Daniel R. Greening

IEEE

Conference

2009

Amir Shatil

Haifa, Israel

Tobin J. Lehman

\begin{tabular}{|l|l|l|}
\hline IEEE & Conference & 2012 \\
\hline IEEE & Conference & 2012 \\
\hline
\end{tabular}




\begin{tabular}{|c|c|c|c|c|c|}
\hline 35 & $\begin{array}{l}\text { The Many Lives of an Agile Story: } \\
\text { Design Processes, Design Products, } \\
\text { and Understandings in a Large-Scale } \\
\text { Agile Development Project }\end{array}$ & Bhawna Rehani & IEEE & Conference & 2011 \\
\hline 36 & $\begin{array}{l}\text { Understanding the Impact of Pair } \\
\text { Programming on Developers Attention } \\
\text { A Case Study on a Large Industrial } \\
\text { Experimentation }\end{array}$ & $\begin{array}{l}\text { Aaron } \\
\text { Nebraska Omaha }\end{array}$ & IEEE & Conference & 2013 \\
\hline 37 & $\begin{array}{l}\text { Scrum Goes Formal: Agile Methods } \\
\text { for Safety-Critical Systems Distributed } \\
\text { agile development: using Scrum in a } \\
\text { large project }\end{array}$ & $\begin{array}{l}\text { Alberto Sillitti, } \\
\text { Bozen Bozen }\end{array}$ & IEEE & Conference & 2013 \\
\hline 38 & $\begin{array}{l}\text { Agile Software Development } \\
\text { Methodology for Medium and large } \\
\text { size projects }\end{array}$ & Sune Wolff Terma A/S & IEEE & Conference & 2013 \\
\hline 39 & Agile Methods for Cloud Computing & $\begin{array}{l}\text { M.Rizwan Jameel } \\
\text { Quereshi }\end{array}$ & IEEE & Conference & 2012 \\
\hline 40 & $\begin{array}{l}\text { Extreme Programming Applied in a } \\
\text { Large-scale Distributed System }\end{array}$ & $\begin{array}{l}\text { S. Kalem, D. Donko and } \\
\text { D. Boskovic }\end{array}$ & IEEE & Conference & 2014 \\
\hline 41 & $\begin{array}{l}\text { The impact of agile principles and } \\
\text { practices on large- scale software } \\
\text { development projects A multiple-case } \\
\text { study of two projects at Ericsson }\end{array}$ & $\begin{array}{l}\text { Elmuntasir Abdullah, } \\
\text { El-Tigani B. Abdelsatir }\end{array}$ & IEEE & Conference & 2014 \\
\hline 42 & $\begin{array}{l}\text { Towards an Agile Feature } \\
\text { Composition for a Large Scale } \\
\text { Software Product Lines }\end{array}$ & $\begin{array}{l}\text { Lina Lagerberg, } \\
\text { Tor Skude, } \\
\text { Pär Emanuelsson and } \\
\text { Kristian }\end{array}$ & IEEE & Journal & 2007 \\
\hline 43 & $\begin{array}{l}\text { Categorization of risk factors for } \\
\text { distributed agile projects }\end{array}$ & $\begin{array}{l}\text { Ikram Dehmouch Mohammed } \\
\text { V Souissi }\end{array}$ & Science Direct & Journal & 2008 \\
\hline 44 & $\begin{array}{l}\text { Process fusion: An industrial case } \\
\text { study on agile software product line } \\
\text { engineering }\end{array}$ & $\begin{array}{l}\text { Suprika V. } \\
\text { Shrivastava ?, } \\
\text { Urvashi Rathod } 1\end{array}$ & Science Direct & Journal & 2011 \\
\hline 45 & $\begin{array}{l}\text { A framework to support the } \\
\text { evaluation, adoption and improvement } \\
\text { of agile methods in practice }\end{array}$ & $\begin{array}{l}\text { Geir K. Hanssen a, } \\
\text { b, *, Tor E. Fægri }\end{array}$ & Science Direct & Journal & 2012 \\
\hline 46 & $\begin{array}{l}\text { "Leagile" software development: An } \\
\text { experience report analysis of the } \\
\text { application of lean approaches in agile } \\
\text { software development }\end{array}$ & $\begin{array}{l}\text { A. Qumer, } \\
\text { B. Henderson-Sellers * }\end{array}$ & Science Direct & Journal & 2013 \\
\hline 47 & $\begin{array}{l}\text { Agile requirements prioritization in } \\
\text { large-scale outsourced system } \\
\text { projects: An empirical study }\end{array}$ & $\begin{array}{l}\text { Xiaofeng Wanga? } \\
\text { Kieran Conboyb } \\
\text {, Oisin Cawleyc }\end{array}$ & Science Direct & Journal & 2014 \\
\hline 48 & $\begin{array}{l}\text { A critical examination of recent } \\
\text { industrial surveys on agile method } \\
\text { usage }\end{array}$ & $\begin{array}{l}\text { Maya Danevaa, } \\
\text { Egbert van der Veena, } \\
\text { Amrita,?, } \\
\text { Smita Ghaisasb, } \\
\text { Klaas Sikkela, Ramesh }\end{array}$ & Science Direct & Journal & 2013 \\
\hline 49 & When agile meets the enterprise & Stavros Stavru? & Science Direct & Journal & 2014 \\
\hline 50 & $\begin{array}{l}\text { Towards a governance framework for } \\
\text { chains of Scrum teams }\end{array}$ & $\begin{array}{l}\text { Guus van Waardenburg } \\
\text { b, Hans van Vliet a,? }\end{array}$ & Science Direct & Journal & 2013 \\
\hline 51 & $\begin{array}{l}\text { Operational release planning in large- } \\
\text { scale Scrum with multiple } \\
\text { stakeholders - A longitudinal case } \\
\text { study at F-Secure Corporation }\end{array}$ & $\begin{array}{l}\text { Jan Vlietland } a \text {, } \\
\text { Hans van Vliet } b \text { ? }\end{array}$ & Science Direct & Journal & 2014 \\
\hline
\end{tabular}

$31,32,33,34,35,36,37,38,39,40,41,42,43,44,45,46,47,48,49,50,51,52,53,54,55,56,57,58,59,60,61,62,63,64]$. 
VII. GRAPHICAL REPRESENTATION OF RESULTS (SLR)

AND SPECIFIC INFORMATION REGARDING RESEARCH PAPER

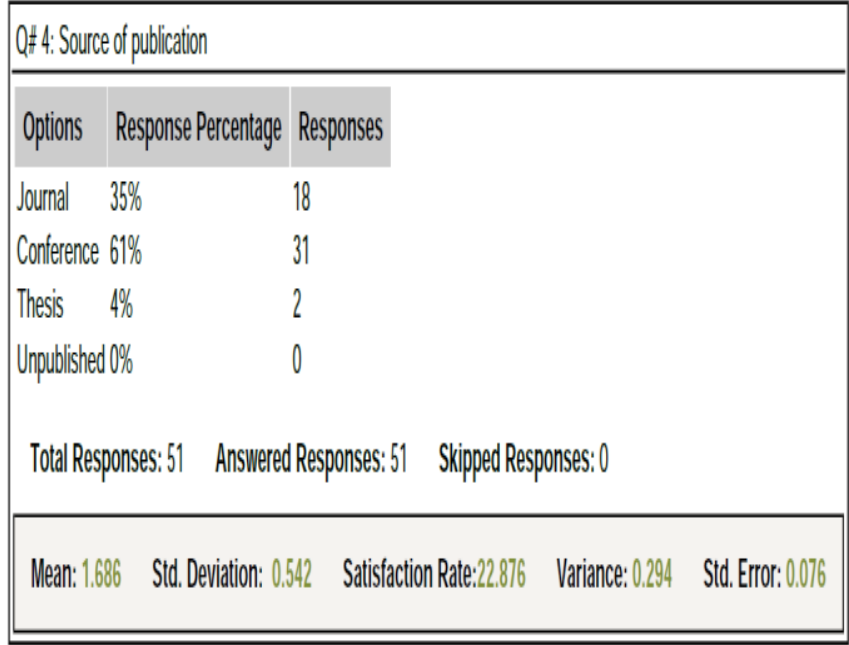

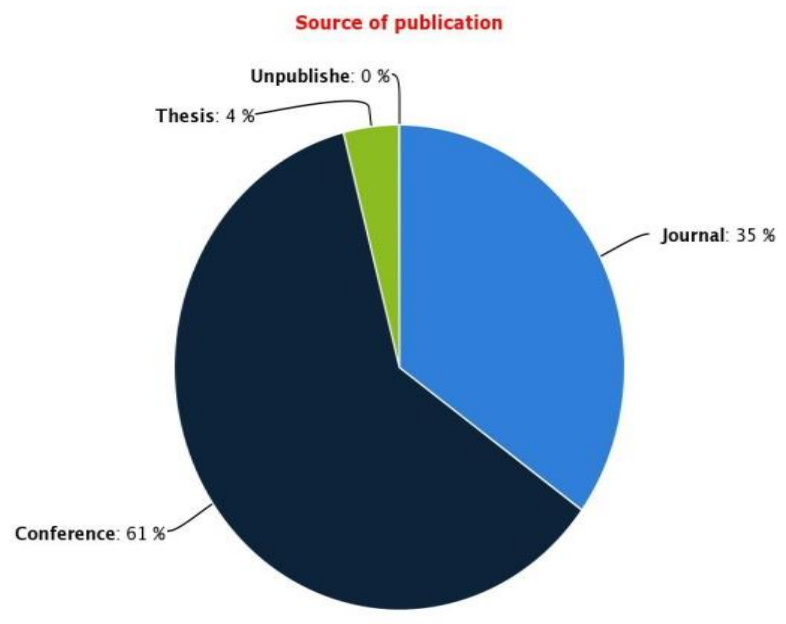

Fig. 1. Source of publication of the paper is?

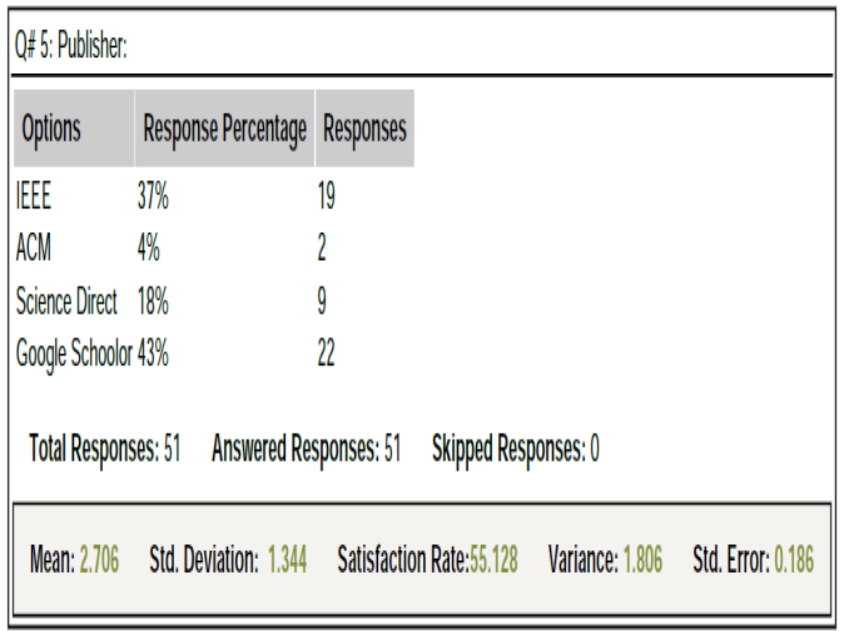

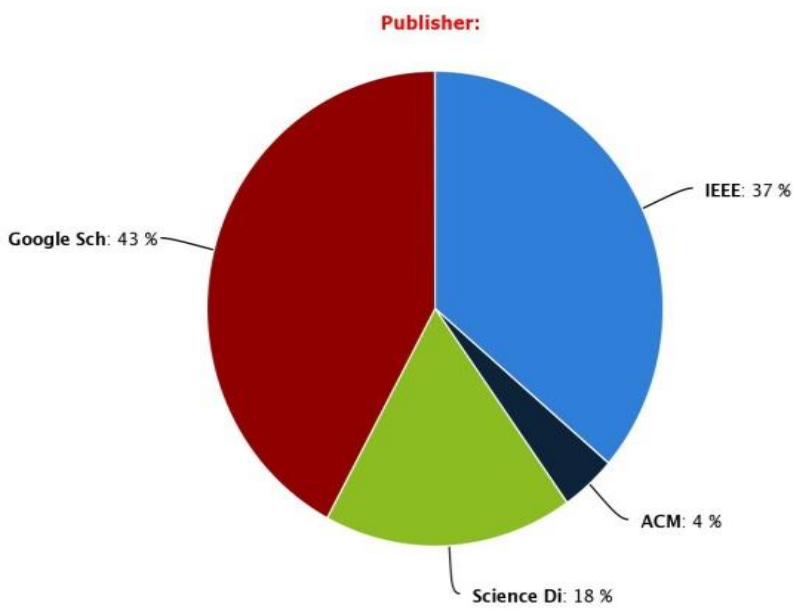

Fig. 2. The study provides information about the publisher of the research papers

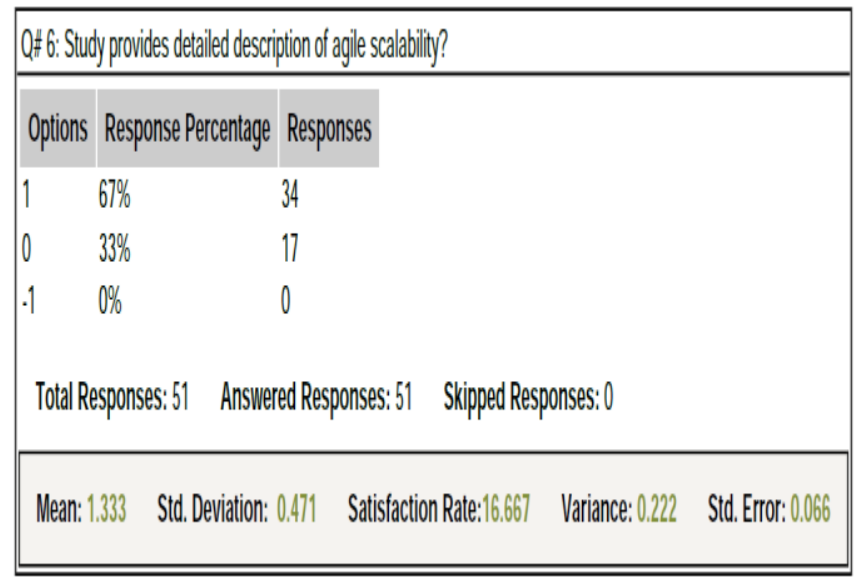

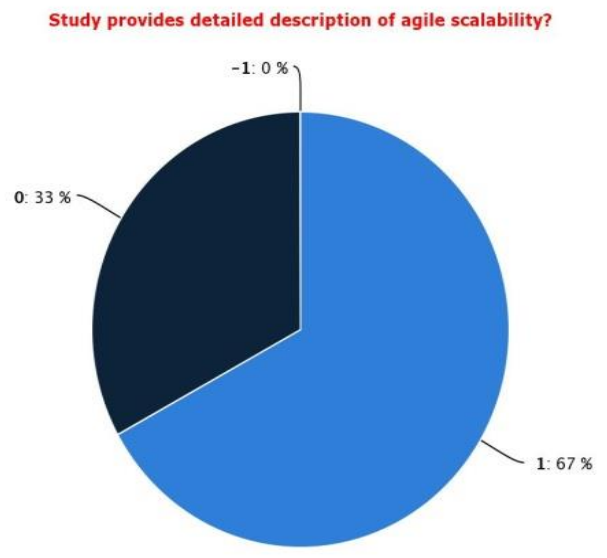

Fig. 3. Study provides detail description of agile scalability 


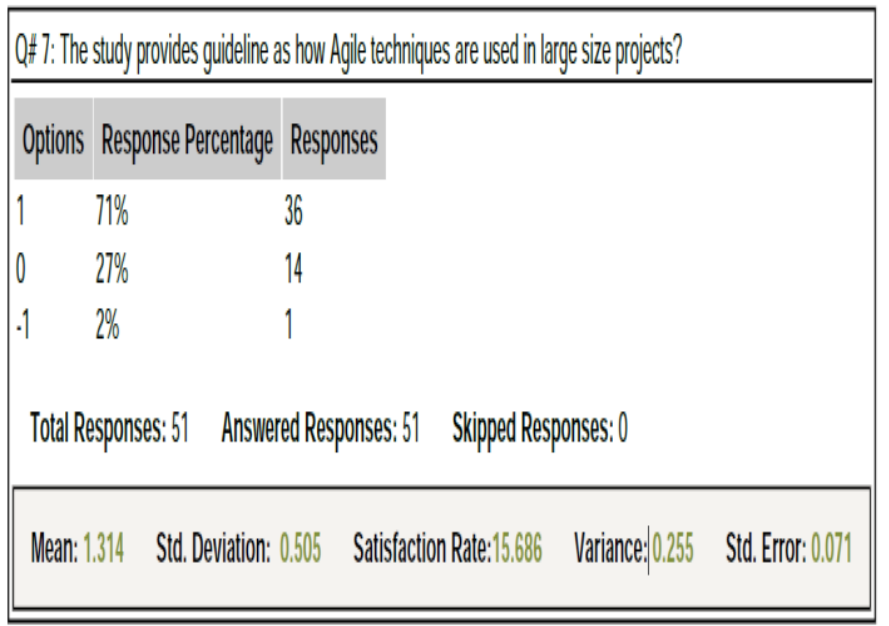

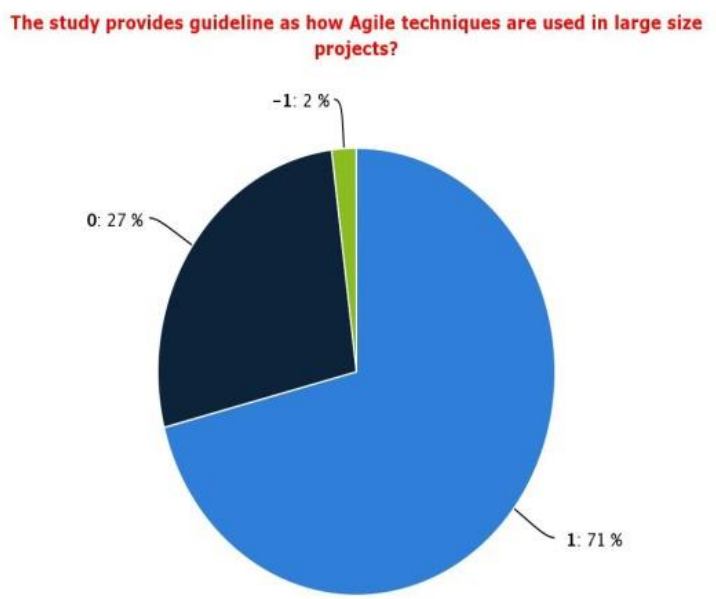

Fig. 4. The study provides guideline as how agile techniques are used in large size projects

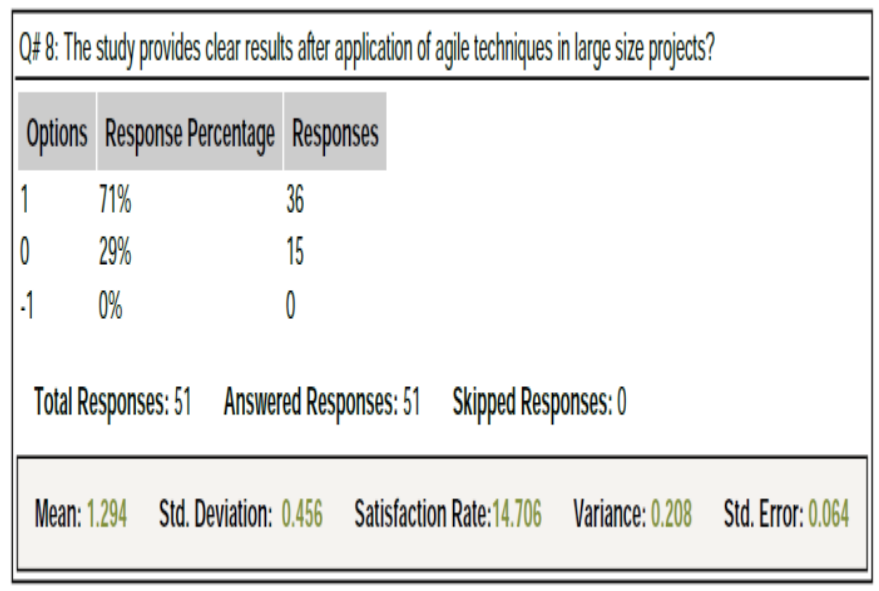

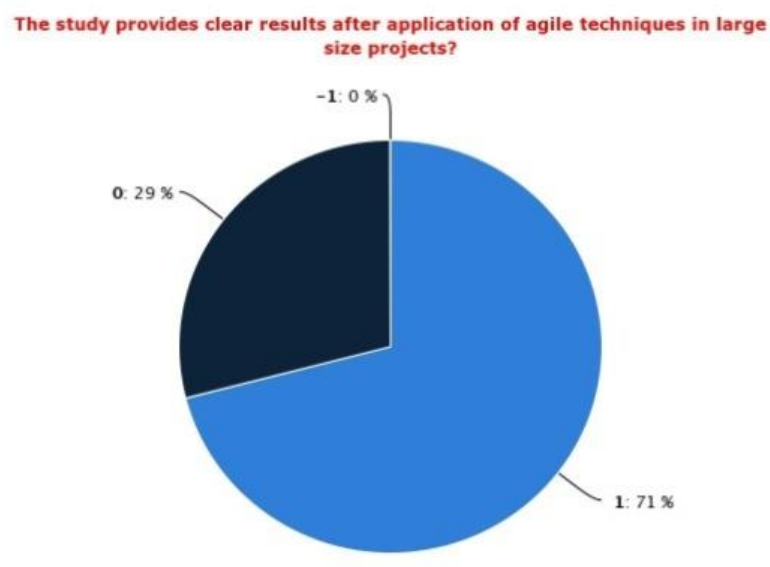

Fig. 5. The study provides clear results after application of agile techniques in large size projects

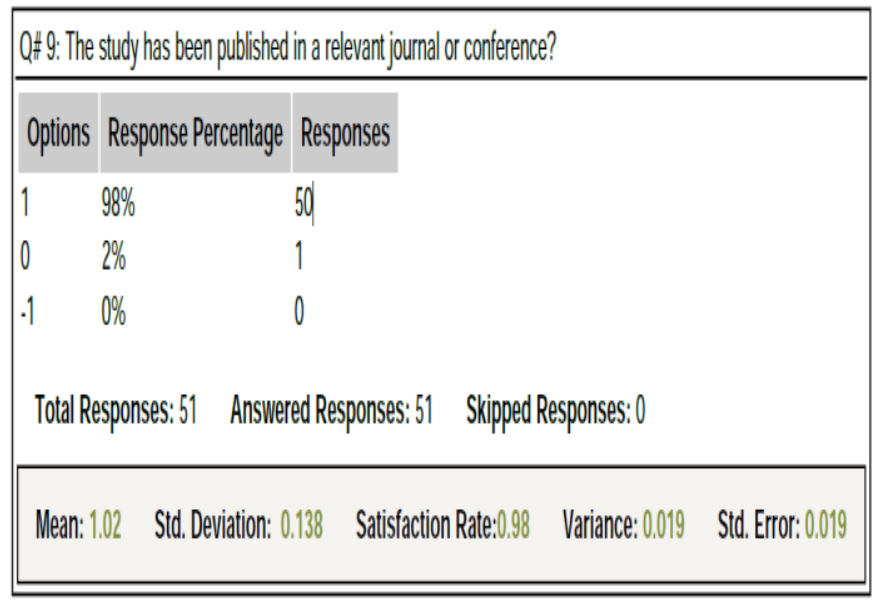

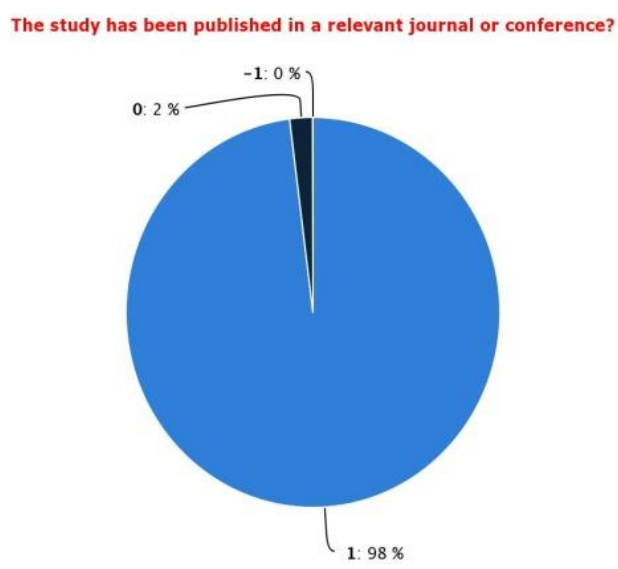

Fig. 6. The study has been published in a relevant journal or conference 


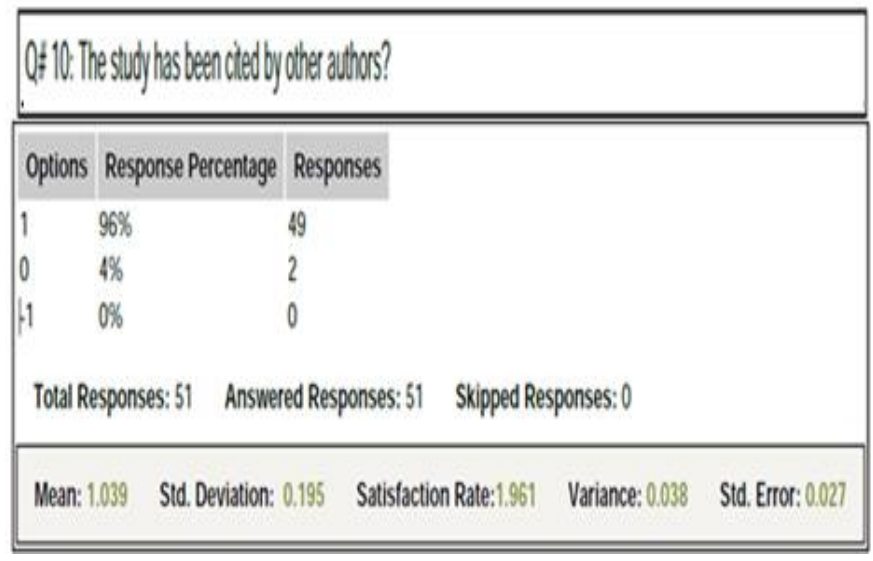

Fig. 7. The study has been cited by authors

\begin{tabular}{|c|c|c|c|}
\hline \multicolumn{4}{|c|}{ Q\# 15: Empirical Validation of the agile techniques applied in large size projects. } \\
\hline Options & Response Percentage & e Responses & \\
\hline Case study & $51 \%$ & 26 & \\
\hline Experiment & $6 \%$ & 3 & \\
\hline Survey & $16 \%$ & 8 & \\
\hline Experience Report & t $22 \%$ & 11 & \\
\hline Observational Study & dy $31 \%$ & 16 & \\
\hline Action Research & $0 \%$ & 0 & \\
\hline Other & $4 \%$ & 2 & \\
\hline Total Responses & es: $51 \quad$ Answered Respo & onses: 51 Skipped Responses: 0 & \\
\hline Mean: 3.804 & Std. Deviation: 1.996 & Satisfaction Rate: 32.323 Variance: 3.986 & Std. Error: 0.24 \\
\hline
\end{tabular}

Fig. 8. Empirical validation of agile techniques in large sized projects

\section{CONCLUSION}

In this SLR performed on agile scalability and adaptability three research questions were made on basis of these three questions research strings were designed using PICOC structure to extract research papers from different data bases including IEEE, Google Scholar, ACM and Science Direct .Search protocol was designed for setting studies rules regulations to follow for summarize and concrete results after analysis.

Inclusion and Exclusion criteria was applied on these selected data bases of papers on basis of set protocol .Papers were selected iteration wise against each research question from these finalized data bases 51 papers were selected , these selected papers were analysed, reviewed and data was extracted based on questions designed in data extraction form.

The study summarized that different researchers made efforts for agile scalability; different techniques of agile scalability are applied for covering agile limitations for scalability limitations.

The gathered data is statistically analysed and according to this analysis research papers selected for study were taken between 2009 -2011, out of 100 percent 35 percent papers were published in journal 61 percent in conference and 4 percent were thesis publications.
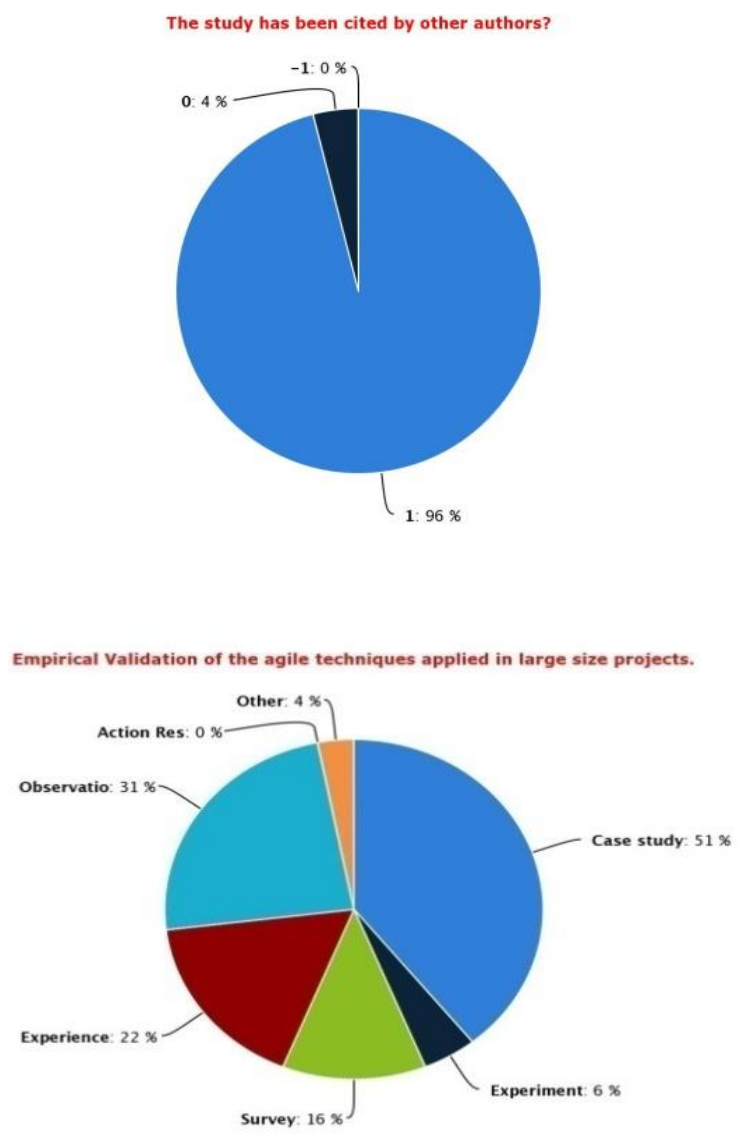

While 37 percent paper's publisher was IEEE, 4 percent ACM, Science Direct was publisher of 18 percent and 43 percent papers were published by Google Scholar.

Form all these selected papers 67 percent papers in detail describe agile adoptability and scalability, 33 percent papers partially discussed the issue .From papers that were answering about agile techniques application 71 percent studies in detail describe the agile techniques application on large scale projects, 27 percent studies partially describe the techniques application and just 2 percent papers are not describing any technique at all.

In SLR 79 percent studies provide clear results of agile application on large size projects, 29 percent are partially providing results of applications, according to analysis, main factor we found was that 88 percent techniques were applied in implementation phase for agile scalability.

Research detect agile limitations for large size projects this question was answered by different researchers and 24 percent researchers said documentation is a limitation for agile practices in large scale projects, 22 percent were saying about time period as a limitation for agile approaches in large scale projects, 14 percent were saying about budget overflow issues in large scale projects while applied agile techniques, 14 percent were talking about human resources related problems in large scale projects while applied agile approaches. 
In SLR conducted 33 percent were talking about team coordination and communication issues and 25 percent were saying that distributed teams are creating limitation for agile applications in large size projects. From these results it is clear that researchers are working on agile scalability and adaptability for large size projects. They are trying to find the exiting limitations as faced by large scale projects while agile approaches are used. They are also working on remedial strategies for agile scalability problems compensation ion large projects.

The aim of this SLR conducted was performing a detailed analysis of the limitations of agility in large size projects and analyzing the existing remedial work and its limitations. From here we extract detail problems analysis, current strategies presents their limitations. We are statistically able to judge the problems, their nature and affect on large size projects

\section{FUTURE WORK}

In future on the basis of these detailed limitations identified in SLR faced by agile approaches some remedial work has to be proposed to handle the highlighted limitations.

\section{REFERENCES}

[1] Hamed, A.M.M.; Abushama, H., (Aug. 2013). Popular agile approaches in software development: Review and analysis. Computing, Electrical and Electronics Engineering (ICCEEE), 2013 International Conference. pp.160,166, 26-28 .

[2] Miller, (2011). The Characteristics of Agile Software Processes. Granville Together Soft. Proceedings of the 39th Int'l Conf. and Exhibition on Technology of Object-Oriented Languages and Systems (TOOLS'01), 1530-2067/01 \$10.00 @ 2001 IEEE

[3] Dot Tudor and George A. Walte, (2006). Using an Agile Approach in a Large, Traditional Project. Proceedings of the conference on AGILE,

[4] Alistair Cockburn, (2001). Book Software Engineering. 1st ed.: Editors copyright Alistair Cockburn.

[5] Dan Turk and Robert France, (2002). Limitations of Agile Software Processes. IN PROCEEDINGS OF THE THIRD INTERNATIONAL CONFERENCE ON EXTREME PROGRAMMING AND FLEXIBLE PROCESSES IN SOFTWARE ENGINEERING (XP).

[6] ProjectVille T. Heikkil"a, Maria Paasivaara and Casper Lassenius , (2013 ). Scrum But, but Does It Matter? A Mixed-Method Study of the Planning Process of a Multi-Team Scrum. ACM / IEEE International Symposium on Empirical Software Engineering and Measurement..

[7] Brian Fitzgerald_, Klaas-Jan Stol_, Ryan O'Sullivan†ं, and Donal O’Brien† _Lero, (2013). Scaling Agile Methods to Regulated Environments: An Industry Case Study . The Irish Software Engineering Research Centre, University of Limerick, Ireland †QUMAS, Cleve Business Park, Monahan Road, Cork, Ireland.

[8] Moore, E.; Spens, J, (Aug. 2008). Scaling Agile: Finding your Agile Tribe. Agile, 2008. AGILE '08. Conference. pp.121, 124.

[9] N. Maiden, (2013). Extending Agile Processes with Creativity Techniques. IEEE Computer Society, B. Hollis , City Univ. London, London, UK. 30, pp.: 78-84

[10] David Bustard , George Wilkie, Des Greer, (2013). The Maturation of Agile Software Development Principles and Practice. ECBS '13 Proceedings of the 20th Annual IEEE International Conference and Workshops on the Engineering of Computer Based Systems IEEE Computer Society Washington, DC, USA.

[11] Aziz Nanthaamornphong, Karla Morris, Damian W. I. Rouson, Hope A. Michelsen, (2013). A case study: agile development in the community laser-induced incandescence modeling environment (CLiiME). Proceeding SE-CSE '13 Proceedings of the 5th International Workshop on Software Engineering for Computational Science and Engineering . ISBN: 978-1-4673-6261-0, pp.9-18
[12] Lagerberg, L. Skude, T. ; Emanuelsson, P. ; Sandahl, K. ; Stahl, D., (2013). The impact of agile principles and practices on large scale software development projects A multiple-case study of two projects at Ericsson . ACM / IEEE International Symposium on Empirical Software Engineering and Measurement..

[13] Ben Othmane, L.; Angin, P.; Weffers, H.; Bhargava, B., , (2014). Extending the Agile Development Process to Develop Acceptably Secure Software,. Dependable and Secure Computing, IEEE Transactions. 11 (6), pp.497,509

[14] Antinyan, V.; Staron, M.; Meding, W.; Osterstrom, P.; Wikstrom, E.; Wranker, J.; Henriksson, A.; Hansson, J, (2014). Identifying risky areas of software code in Agile/Lean software development: An industrial experience report. Software Maintenance, Reengineering and Reverse Engineering (CSMR-WCRE), 2014 Software Evolution Week - IEEE Conference. (), pp. 154,163

[15] Scheerer, A.; Hildenbrand, T.; Kude, T., (2014). Coordination in LargeScale Agile Software Development: A Multiteam Systems Perspective. System Sciences (HICSS), 2014 47th Hawaii International Conference ..pp.4780,4788,

[16] Olsson, H.H.; Bosch, J.; Alahyari, H.,, (2013). Customer-Specific Teams for Agile Evolution of Large-Scale Embedded Systems. Software Engineering and Advanced Applications (SEAA), 2013 39th EUROMICRO Conference,pp.82,89.

[17] Farrow, A.; Greene, S, (2008). Fast \& Predictable A Lightweight Release Framework Promotes Agility through Rhythm and Flow. Agile, 2008. AGILE '08. Conference, pp.224,228.

[18] Blau, B.; Hildenbrand, T, (2011). Product Line Engineering in LargeScale Lean and Agile Software Product Development Environments Towards a Hybrid Approach to Decentral Control and Managed Reuse. Availability, Reliability and Security (ARES), 2011 Sixth International Conference, pp.404,408 .

[19] Khan, M.I.; Qureshi, M.A.; Abbas, Q.(2010). Agile methodology in software development (SMEs) of Pakistan software industry for successful software projects (CMM framework). (ICENT), 2010 International Conference, pp.576, 580.

[20] Pearl Brereton a,*, Barbara A. Kitchenham a, David Budgen b,Mark Turner a, Mohamed Khalil c, (2006). Lessons from applying the systematic literature review process within the software engineering domain. Department of Computer Science, Durham University, Durham, Science Laboratories, South Road, Durham City, DH1 3LE, UKc Department of Computer Sciences, University of Khartoum, P.O. Box 321, Khartoum, Sudan.

[21] Subhas C. Misra, Vinod Kumar, Uma Kumar, (2009). Identifying some important success factors in adopting agile software development practices. Journal of Systems and Software. 82 pp.1869-1890

[22] Minna Pikkarainen \& Outi Salo \& Raija Kuusela \& Pekka Abrahamsson, (2011). Strengths and barriers behind the successful agile deploymentinsights from the three software intensive companies in Finland. Springer Science+Business Media.

[23] Frank K.Y. Chan, James Y.L. Thong , (2009). Acceptance of agile methodologies: A critical review and conceptual framework. Department of Information Systems, Business Statistics and Operations Management, School of Business and Management, Hong Kong University of Science and Technology, Clear Water Bay, Kowloon, Hong Kong .

[24] Kuda Nageswara Rao, G. Kavita Naidu, Praneeth Chakka , (2011). A Study of the Agile Software Development Methods, Applicability and Implications in Industry . International Journal of Software Engineering and Its Applications. 5.

[25] [Mengjiao Shen; Wenrong Yang; Guoping Rong; Dong Shao, (2012). Applying agile methods to embedded software development: A systematic review," Software Engineering for Embedded Systems (SEES),. 2nd International Workshop. Pp.30-36.

[26] Smits, H, (2007). The Impact of Scaling on Planning Activities in an Agile Software Development Center,. 40th Annual Hawaii International Conference, pp.274c.

[27] Salo, O.; Abrahamsson, P, (2008). Agile methods in European embedded software development organizations: a survey on the actual 
use and usefulness of Extreme Programming and Scrum, Software, IET. 2 pp.58 and 64 .

[28] Gabrielle Benefield, (2008). Rolling out Agile in a Large Enterprise Proceedings of the 41st Hawaii International Conference on System Sciences.

[29] Taromirad, M.; Ramsin, R, (2008), An Appraisal of Existing Evaluation Frameworks for Agile Methodologies, Engineering of Computer Based Systems, ECBS 2008. 15th Annual IEEE International Conference and Workshop pp.418, 427.

[30] Laanti, M, (2008) Implementing Program Model with Agile Principles in a Large Software Development Organization,Computer Software and Applications, 2008. COMPSAC '08. 32nd Annual IEEE International, pp.1383, 1391.

[31] Soundararajan, S.; Arthur, J.D.,( 2009) A Soft-Structured Agile Framework for Larger Scale Systems Development," Engineering of Computer Based Systems,. ECBS 2009. 16th Annual IEEE International Conference and Workshop pp.187, 195.

[32] E. Murphy-Hill, L. Williams, (2003), Agile software development: it's about feedback and change, North Carolina State University; Computer; 36(6): DOI: 10.1109/MC.2003.1204373 Source: IEEE Xplore, pp. 3943.

[33] Hajjdiab, H.; Taleb, A.S.,(2011), Agile adoption experience: A case study in the U.A.E, Software Engineering and Service Science (ICSESS), 2011 IEEE 2nd International Conference on , vol., no., pp.31,34, 15-17 July 2011 doi: 10.1109/ICSESS.2011.5982247

[34] Mary Wu, (2011), Agile Method to Improve Delivery of Large-Scale Software Projects, Presented to The Faculty of the Department of General Engineering Son Jose State University.

[35] W. Ambler , (2011). Methodologist for Agile and Lean, IBM Rational IBM agility@scaleTM: Become as Agile as You Can Be.1st ed.

[36] Deepti Mishra,$\dagger$ and Alok Mishra, (2011). Complex software project development: agile methods adoption. JOURNAL OF SOFTWARE MAINTENANCE AND EVOLUTION: RESEARCH AND PRACTICE J. Softw. Maint. Evol.: Res. Pract. (2011) . (), pp.

[37] Reifer, D.J, (2003). XP and the CMM," Software. IEEE. 20 , pp.e.g. 1415.

[38] Paulk, M.C,(2011), Extreme programming from a CMM perspective, Software, IEEE, vol.18, no.6, pp.19,26.

[39] Elssamadisy A, (2001), XP on a large project-A developer's view, Proceedings of XP/Agile Universe, Raleigh NC, 2001.

[40] Petersen K, Wohlin C, (2009), A comparison of issues and advantages in agile and incremental development between state of the art and an industrial case, Journal of Systems and Software 2009; 82(9), pp. 14791490 .

[41] Soundararajan S, Arthur JD, (2009). A soft-structured agile framework for larger scale systems development.. Proceedings of the 2009 16th Annual IEEE international Conference and Workshop on the Engineering of Computer Based Systems.ECBS. IEEE Computer Society: Washington DC, 2009; 187195.

[42] Sidky A, Arthur J, (2007). Determining the applicability of agile practices to mission and life-critical systems. Proceedings of the 31st IEEE Software Engineering Workshop,(SEW 2007). IEEE Computer Society: Reading MA, 2007; 3-12. DOI: 10.1109/SEW.2007.61.

[43] Chuan-Hoo Tan, Wee-Kek Tan, Hock-Hai Teo Hock-Hai Teo, (2013). Designing an Information Systems Development Course to Incorporate Agility, Flexibility, and Adaptability . Volume 26 Article 10 . (), pp.

[44] Jutta Eckstein , (2009). Agile Software Development in the Large Encontro Ágil . Large Encontro Ágile. ISBN 0-932633-57-9 (), pp.233

[45] REHAN AKBAR, MUHAMMAD HARIS, MAJID NAEEM, (2008). Agile Framework for Globally Distributed Development Environment (The DAD Model) . 8th WSEAS International Conference on APPLIED INFORMATICS AND COMMUNICATIONS (AIC'08) . (), pp.

[46] Abbass Ghanbary , (2010). Success of Agile Environment in Complex Projects. Edith Cowan University Research Online Australian Information Warfare and Security Conference.. (), pp.

[47] Begel, A.; Nagappan, N, (2007). Usage and Perceptions of Agile Software Development in an Industrial Context: An Exploratory Study. Empirical Software Engineering and Measurement, 2007. ESEM 2007.
First International Symposium. (), pp.255-264, doi: 10.1109/ESEM.2007.12 .

[48] Isham M, (2008). Agile Architecture IS Possible You First Have to Believe. Agile, 2008. AGILE '08. Conference. (), pp.484,489 , doi: 10.1109/Agile.2008.16.

[49] John D. McGregor , (2008). Agile Software Product Lines - A Working Session. 12th International Software Product Line Conference IEEE Computer Society Washington, DC, USA @2008. ISBN: 978-0-76953303-2, doi:10.1109/SPLC.2008.60.

[50] Gul, E.; Sekerci, T.; Yuceturk, A.C.; Yildirim, U, (2008). Using XP in Telecommunication Software Development. Software Engineering Advances, 2008. ICSEA '08. The Third International Conference . e.g. 32 (), pp.258,263. doi: 10.1109/ICSEA.2008.11

[51] Jianbin; Shi Tong; Fang Deying, (2009). A Heavy Weight IT Project Management Framework Based on Agile Theory. Management and Service Science, 2009. MASS '09. International Conference . (), pp.1-5 , doi: 10.1109/ICMSS.2009.5301737.

[52] VanderLeest, S.H.; Buter, A, (2009). Escape the waterfall: Agile for aerospace. Digital Avionics Systems Conference, 2009. DASC '09. IEEE/AIAA 28th. $\quad(), \quad$ pp.6 doi: 10.1109/DASC.2009.5347438.

[53] Lehman, T.J.; Sharma, A, (2011), Software Development as a Service: Agile Experiences, SRII Global Conference (RII), 2011 Annual , vol., no., pp.749,758, March 29 2011-April 22011 doi: 10.1109/SRII.2011.82.

[54] Read, A.; Briggs, R.O, (2012), The Many Lives of an Agile Story: Design Processes, Design Products, and Understandings in a LargeScale Agile Development Project, System Science (HICSS), 2012 45th Hawaii International Conference on , vol., no., pp.5319,5328, 4-7 Jan. 2012 , doi: 10.1109/HICSS.2012.684.

[55] S. Kalem, D. Donko and D. Boskovic , (2013). Agile Methods for Cloud Computing . Faculty of Electrical Engineering, University of Sarajevo, Bosnia and Herzegovina . (), pp.

[56] Suprika V. Shrivastava $\Uparrow$, Urvashi Rathod , (2015). Categorization of risk factors for distributed agile projects. Symbiosis Centre for Information Technology (SCIT), Symbiosis International University (SIU), Rajiv Gandhi Infotech Park, Hinjewadi, Pune 411 057, Maharashtra, India. Information and Software Technology journal homepage. 58 (), pp.

[57] Geir K. Hanssen a,b,*, Tor E. Fægri a , (2007). Process fusion: An industrial case study on agile software product line engineering . SINTEF ICT, NO-7465 Trondheim, Norway b Norwegian University of Science and Technology, Department of Computer and Information Science, NO-7491 Trondheim, Norway . (), pp.

[58] A. Qumer, B. Henderson-Sellers, (2008). A framework to support the evaluation, adoption and improvement of agile methods in practice. Faculty of Information Technology, University of Technology, Sydney, P.O. Box 123, Broadway 2007, Australia. (), pp.

[59] Xiaofeng Wanga,*, Kieran Conboyb, (2012). Leagile" software development: An experience report analysis of the applicationof lean approaches in agile software development. Oisin Cawleyca Free University of Bozen/Bolzano, Italyb School of Information Systems, Technology and Management, UNSW, Sydney 2052, Australiac Lero, The Irish Software Engineering Research Centre, Ireland The Journal of Systems and Software. 85 (), pp.

[60] Stavros Stavru*,St. Kliment Ohridski, (2014). A critical examination of recent industrial surveys on agile method usage. The Journal of Systems and Software 94 (2014) 87-97, pp.

[61] Guus van Waardenburg b, Hans van Vliet a, (2013). When agile meets the enterprise . a VU University Amsterdam, De Boelelaan 1081, 1081 HV Amsterdam, The Netherlands b Avanade Netherlands, Versterkerstraat 6,1322 AP Almere, The Netherlands Information and Software Technology 55 (2013) 2154-2171.. (), pp.

[62] Jan Vlietland a, Hans van Vliet b,, , (2015). Towards a governance framework for chains of Scrum teams. The Netherlands b Department of Computer Science, VU University Amsterdam, Amsterdam, the Netherlands. Information and Software Technology 57 (2015) 52-65.. (), pp. 
[63] Hina Saeeda , Fahim Arif (20150 Agile Scalability for Large Scale Projects: Lessons Learned. Computer Software Department MCS NUST, JSW $2015 \quad$ Vol.10(7):893-903ISSN:1796-217X doi: $10.17706 / /$ jsw.10.7.893-903

[64] Hina SAEEDA, FAHIM ARIF (20150 AgILE SCALABILITY FOR LARGE Scale Projects: Lessons Learned. COMPuter Software DEPARTMENT MCS NUST, JSW 2015 VOL.10(7):893-903ISSN:1796217X DOI: $10.17706 / / \mathrm{JSW} .10 .7 .893-903$

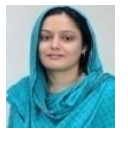

\section{AUTHOR PROFILE}

Hina Saeeda received her BS (CS) degree in 2011 from the Arid Agriculture University and received MS in Software Engineering degree from NUST, Pakistan in 2015. Her current research interests include agile software Engineering, and usability engineering. She is a lecturer of Computer Sciences by profession.

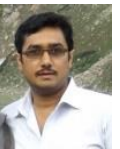

Hannan Khalid received his BS (hons) degree in Computer Science in 2012 from the Arid Agriculture University and is now conducting research towards completion of his Masters' degree in Software Engineering from COMSATS Institute of Information technology, Islamabad, Pakistan. His current research interests include information system theories, and techniques for requirement engineering. He started his professional career in 2013 as a software quality assurance engineer and has worked with multiple projects since then.

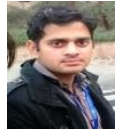

Mukhtar Ahmed is doing MS in Software Engineering from COMSATS Institute Of Information Technology, Islamabad, Pakistan. He did his BS in Software Engineering from university of Azad Jammu and Kashmir in 2011. His allegiance to work and preeminent nature guided him to learn different research issues from different platforms. His research interests are information system, and Global software development (GSD).

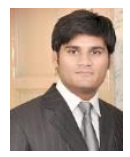

Abu Sameer earned his Bachelor's in Software Engineering in 2013 from University Of Sargodha Pakistan. He completed his MS degree in Software Engineering form COMSATS Institute of Information Technology, Islamabad, Pakistan in 2015. He has an affirm attitude towards research and is working as a research assistant. Moreover he is an active adroit member of Agile Software Development research committee at COMSATS Institute Of Information Technology Islamabad Pakistan.

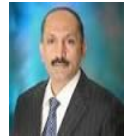

Fahim Arif was born in 1967, is currently professor at MCSNUST Pakistan. He received Master in Sciences in Computer Software Engineering degree from National University Science and Technology, Islamabad in 2003. He has completed his PhD degree from National University Science and Technology in 2009. His research interest is quality assurances, software engineering and image processing. 